\title{
CDC's Efforts to Quantify Prescription Opioid Overdose Deaths Fall Short
}

John F. Peppin · John J. Coleman (D)

Received: December 9, 2020 / Accepted: March 6, 2021 / Published online: March 24, 2021

(c) The Author(s) 2021

\begin{abstract}
In a 2018 report titled, Quantifying the Epidemic of Prescription Opioid Overdose Deaths, four senior analysts of the Centers for Disease Control and Prevention (CDC), including the head of the Epidemiology and Surveillance Branch, acknowledged for the first time that the number of prescription opioid overdose deaths reported by the CDC in 2016 was erroneous. The error, they said, was caused by miscoding deaths involving illicitly manufactured fentanyl (IMF) as deaths involving prescribed fentanyl. To understand what caused this error, the authors examined the CDC's methodology for compiling drug-related mortality data, beginning with the source data obtained from approximately 2.8 million death certificates received each year from state vital statistics registrars. Systemic problems often begin outside the CDC, with a
\end{abstract}

J. F. Peppin

College of Osteopathic Medicine, Pikeville

University, Pikeville, KY, USA

J. F. Peppin

Marian University College of Osteopathic Medicine, Indianapolis, IN, USA

J. F. Peppin

John F. Peppin, DO, FACP, LLC, Lexington, KY, USA

J. J. Coleman ( $\varangle)$

Drug Watch International, Inc, Clifton, VA, USA

e-mail: john.coleman.phd@gmail.com surprisingly high rate of errors and omissions in the source data. Using the CDC's explanation for what caused the error, the authors show why an international program used by the CDC for reporting mortality is ill-suited for compiling and reporting drug overdose deaths. Except for heroin, methadone, and opium, each of which has an individual program code, all other opioids are separated in just two program codes according to whether they are synthetic or semisynthetic/opiates. Methadone-involved deaths pose a special problem for the CDC because methadone has dual indications for treating pain and for treating opioid use disorder (OUD). In 2019, more than seven times more methadone was administered or dispensed for OUD treatment than was prescribed for pain, yet all methadone-involved deaths are coded by the CDC as involving the prescribed form of the drug. The authors conclude that the CDC was at fault for failing to recognize and correct this problem before 2016. Public policy consequences of this failure are briefly mentioned.

Keywords: Centers for Disease Control and Prevention (CDC); Death certificates; Illicitly manufactured fentanyl (IMF); International Classification of Diseases (ICD); Methadone; Prescription opioid overdose deaths 


\section{Key Summary Points}

The Centers for Disease Control and Prevention (CDC) erroneously reported prescription opioid overdose deaths in 2016 and for more than a decade before.

The error was traced to miscoding of illicitly manufactured fentanyl as prescribed fentanyl, using defined T-codes of the International Classification of Diseases.

Systemic errors begin with error-prone death certificate information provided to the CDC by state registrars of vital statistics.

Besides the fentanyl error, similar limitations were noted for other controlled substances, notably benzodiazepines, cocaine, and methadone.

Most methadone today is used for treating opioid use disorder for which it must be administered or dispensed but not prescribed, according to federal law.

Yet, the CDC characterizes all methadonerelated overdose deaths as involving the prescribed version used to treat pain; thus the integrity of the CDC's prescription drug mortality data remains in question.

The CDC was aware of the error involving fentanyl coding as early as 2005-2007 when illicitly manufactured fentanyl was noted by the CDC in more than a thousand overdose deaths in the U.S.

Yet, the CDC ignored the problem until 2016 data showed serious inconsistencies with other, more reputable, data for prescribing volumes of opioids.

In 2018, the U.S. Congress mandated the CDC to "modernize" its system for reporting drug overdose deaths but this has not yet occurred.

\section{DIGITAL FEATURES}

This article is published with digital features, including a summary slide, to facilitate understanding of the article. To view digital features for this article go to https://doi.org/10.6084/ m9.figshare.14141753.

\section{MORTALITY SOURCE DATA: THE DEATH CERTIFICATE}

Since 1960, the federal collection of mortality data has been the task of the National Center for Health Statistics (NCHS), a subdivision of the CDC [1]. The National Vital Statistics System (NVSS), a program within the NCHS, compiles and publishes the nation's vital statistics [1]. CDC guidelines for completing death certificates require certifiers to list a single cause of death along with a brief description of the sequence and timing of events immediately leading up to death. In part II of the Death Certificate, a certifier may include up to 20 contributory causes of death [2].

In most instances when death occurs in a clinical setting, the attending physician will complete and certify the cause of death. Timelines and procedures for reporting and investigating deaths are set by state law and vary among states and even within states [3]. Suspected drug overdose deaths and other types of suspicious or accidental deaths must be referred to medical examiners or coroners for investigation, according to state laws. Upon completion, death certificates are forwarded to state registrars who electronically transmit portions, including cause of death entries, to the NCHS for inclusion in the National Death Index [4] (see Fig. 1).

\section{DRUG OVERDOSE DEATHS POSE UNIQUE PROBLEMS FOR IDENTIFYING CAUSE OF DEATH}

Multiple studies show that death certificate errors are common, especially in drug overdose 


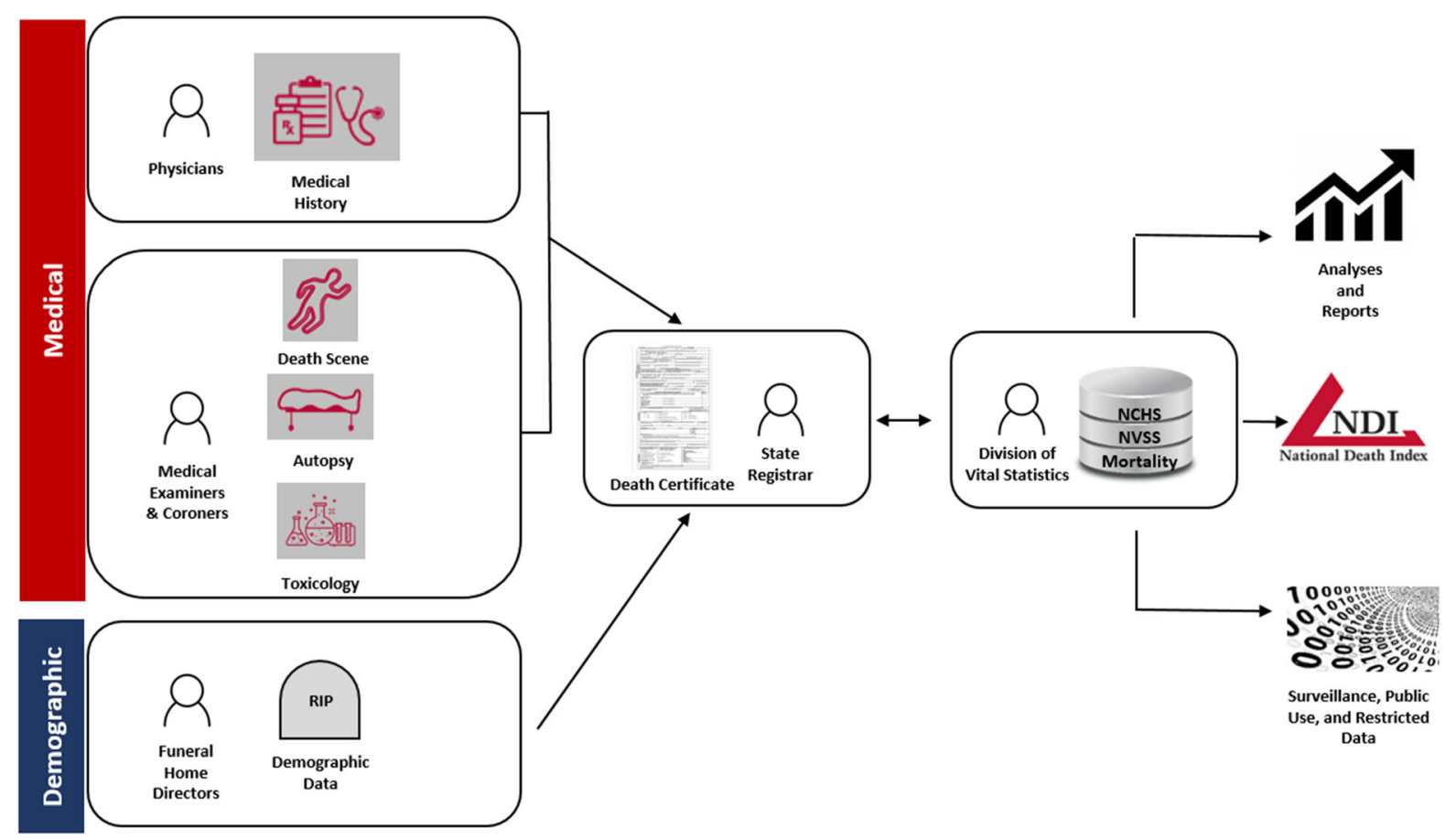

Fig. 1 How mortality source data are collected in the U.S. and converted into vital statistics. (source: Robert N. Anderson, Ph.D., Chief, Mortality Statistics Branch, Centers for Disease Control and Prevention; permission granted 02/25/2021)

cases in which preliminary death certificates are often issued before postmortem toxicology results are known [5-10]. Dr. Robert Anderson, chief of the mortality statistics branch of the NCHS, acknowledges that between 20 and 30\% of death certificates received by the NCHS are incorrect [11].

In drug-related cases, the CDC recommends that a supplemental death certificate be issued after toxicology findings are known, but this advice is not always followed, especially when the preliminary death certificate lists a cause of death as "drug overdose," "multiple drug toxicity," or some other similarly ambiguous cause that, while true, has little epidemiological value [2].

Each year, the NVSS receives approximately 2.8 million death records from state registrars [12]. These records, including cause of death data extracted from death certificates, are entered into the NVSS database by technicians using specialized software that converts the literal language of the death certifier into category codes defined by the International Classification of Diseases (ICD), a taxonomy produced and managed by the World Health Organization $[2,12]$. With few exceptions for infrequent and rare causes of death, the NVSS accepts the data, as is, without verifying accuracy or completeness [13]. Thus, the CDC begins its task of compiling and analyzing national mortality data with unfiltered source data that, according to the chief of the mortality statistics branch, has an acknowledged error rate between 20 and $30 \%$ [11].

\section{THE FINAL DIAGNOSIS}

Drug overdose deaths in the U.S. amount to a fraction of all deaths (about 3\%) each year, but as a proportion of accidental deaths-deaths that are caused by unintentional and preventable injuries-they account for more than a third (38\%) [14]. Most drug overdose deaths are categorized by the CDC and ICD as unintentional poisoning deaths [14].

A fatal drug overdose may result from consuming, smoking, and/or injecting a toxic substance or, as more often is the case, from self- 
administering a combination of toxic substances, the latter situation making the postmortem identification of a single causative agent difficult and sometimes impossible [15]. Toxicology tests typically detect multiple psychoactive substances, including cannabis, opioids, benzodiazepines, and/or stimulants such as methamphetamine or cocaine. Often, these drugs are accompanied by alcohol (ethanol), a substance that can alter the metabolism or activity of other drugs, resulting in serious or fatal pharmacodynamic interactions [15]. The use of drugs in combination can produce a hazardous additive effect with increased central nervous system suppression and a heightened risk of fatal overdose [16].

Although most fatalities involving opioids are polysubstance overdose deaths, the essence of this is not captured in the death certificate where regulations require certifying a single cause of death, along with a brief list of sequential events leading up to the single cause [17]. The notion that one or multiple drugs might potentiate the action of another drug to cause death is all but lost in the manner in which drug overdose death cases are typically reported. Ignoring the potential for toxic drug interactions risks misrepresenting the actual cause of death [18].

\section{THE INTERNATIONAL CLASSIFICATION OF DISEASES (ICD)}

Originally developed to classify mortality and to provide a coding schema for listing causes of death, the ICD has expanded over the years to include classifying morbidity and many other items and procedures related to the delivery of healthcare [19]. In the U.S., the ICD consists of two components, identified as ICD-10-CM, for clinical modifications, and ICD-10-PCS, for procedural coding system.[19]

The NCHS, with guidance from the Centers for Medicare and Medicaid Services, is responsible for developing the ICD-10's clinical modifications used in the U.S. [19]. Chapter 19 of the ICD-10 provides two subcategories identified as $S$ and $T$ codes [20]. The $S$ codes are for various single body region injuries, and the $\mathrm{T}$ codes cover injuries to unspecified body locations, poisonings, and other external consequences [20].

Six T-codes identify all opioids: Opium (T40.0); Heroin (T40.1); Natural and Semisynthetic Opioids (including morphine, codeine, oxycodone, hydrocodone, hydromorphone, and oxymorphone) (T40.2); Methadone (T40.3); Synthetic Opioid Analgesics Other Than Methadone (including fentanyl, meperidine, pentazocine, propoxyphene, tapentadol, buprenorphine, and tramadol) (T40.4); and, finally, Other and Unspecified Narcotics (T40.6) [21] (see Fig. 2).

Until 2016, the NVSS calculated annual mortality involving prescription opioids by summing deaths identified by ICD codes T40.2, T40.3, and T40.4 [22]. In 2016, the sum of these three codes amounted to 32,445 deaths [22] (see Table 1). Code T40.4 was identified as the source of the error described by the CDC analysts [22]. This systemic error likely began in 2005-2007, when the CDC and the Drug Enforcement Administration (DEA) identified 1013 deaths caused by illicitly manufactured fentanyl (IMF) mixed with, and sold as, heroin in several mid-western and northeastern states [23].

In 2013, IMF reappeared, causing deaths in the northeast [23]. The CDC was informed by Rhode Island authorities that acetyl fentanyl, a fentanyl analog up to five times as potent as fentanyl, had been identified in ten drug overdose deaths in the state between March 7 and April 11, 2013 [24]. During and shortly after the month-long investigation in Rhode Island, four more overdose deaths occurred [24]. Besides the Rhode Island deaths, a CDC field report at the time cited a cluster of 50 similar IMF deaths reported by authorities in Pennsylvania [24].

Despite having information about IMF since the 2005-2007 outbreak, the NVSS continued to code all incoming death certificate information that mentioned fentanyl as a single or contributory cause of death as the prescribed form of the drug, a serious miscalculation that would have substantial consequences on public policy, health, and safety. 


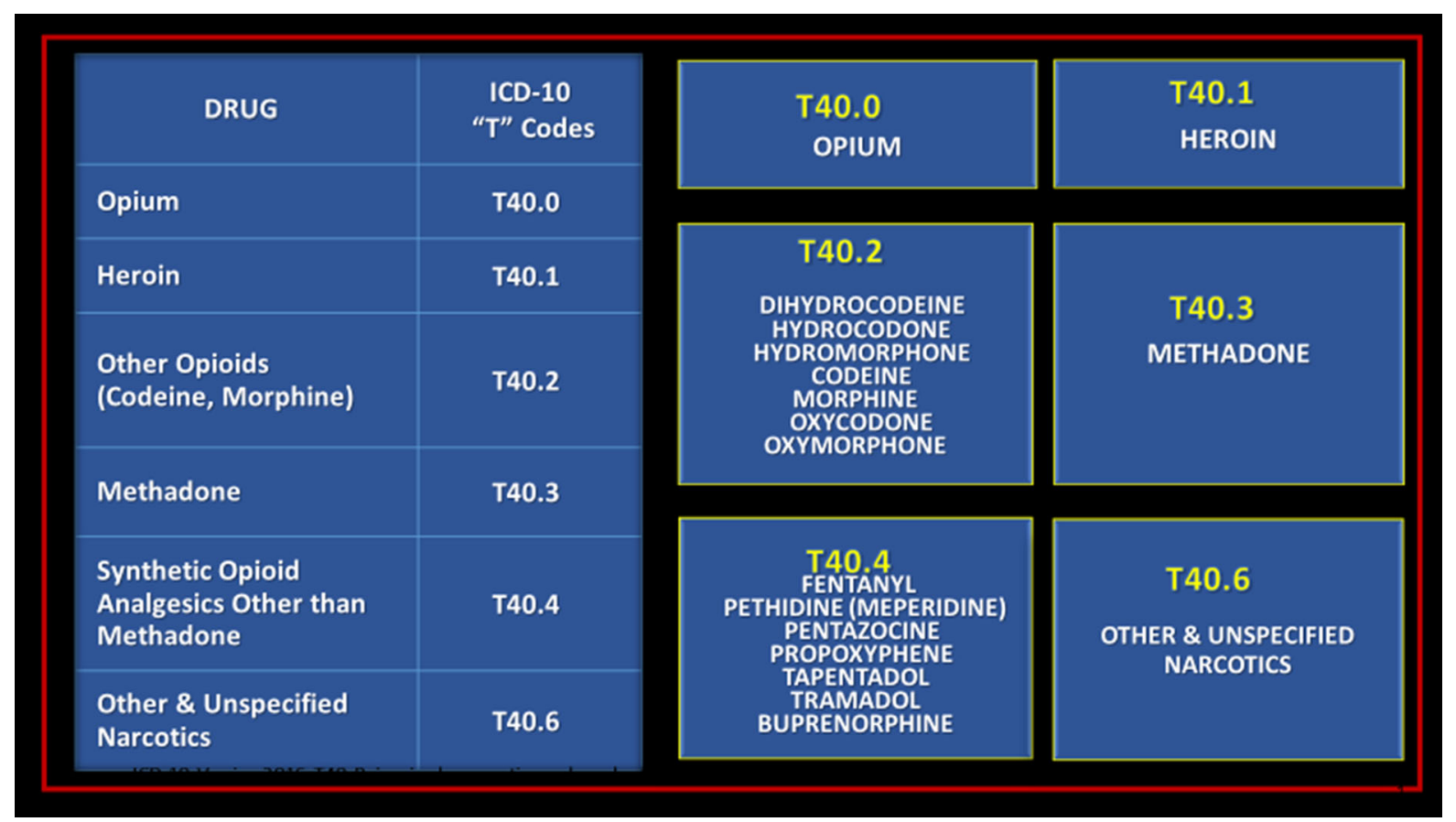

Fig. 2 A chart showing the T-codes for opioids as categorized by the International Classification of Diseases, Tenth Edition, 1999-2022 (ICD-10) (Chart source: [53])

Two years after discovering their error in the 2016 figures for prescription opioid overdose deaths, the CDC analysts proposed what they called a "conservative" method for re-calculating the numbers [22]. Their conservative method simply removed all deaths coded T40.4 [22]. This reduced the number of prescription opioid deaths in 2016 from 32,445 to $17,087-a$ sizable drop of $47.3 \%$ [22]. The analysts acknowledged, however, that their conservative approach likely produced an undercount because by deleting all deaths coded T40.4, they were removing overdose deaths involving prescription fentanyl, as well as overdose deaths involving other synthetic opioids other than methadone identified by the same T40.4 code (e.g., meperidine, pentazocine, propoxyphene, tapentadol, buprenorphine, and tramadol) [22]

Congress addressed this issue in October 2018, when the Support for Patients and Communities Act was passed and signed into law by the president [25]. The Act directed the CDC to modernize its system for coding causes of deaths related to drug overdoses [25].

\section{OPIOID CODING NOT THE ONLY FLAW IN THE CDC'S METHODOLOGY}

The discovery of the T-code error in the CDC's prescription opioid overdose death statistic for fentanyl in 2016 prompted the authors to search for flaws and limitations elsewhere in the CDC's coding of controlled substances. They discovered that benzodiazepines, a class of drugs often associated with fatal opioid drug overdoses, are undifferentiated in ICD T-codes [21]. More than a dozen FDA-approved benzodiazepine drugs are identified by a single ICD T-code (T42.4) [21]. In 2018, according to the National Institute on Drug Abuse, benzodiazepines were involved in $15.8 \%$ of all drug overdose deaths [26] (see Fig. 3).

While single coding benzodiazepines is not an error, per se, it limits the epidemiological value of the data by not identifying specific benzodiazepines associated most often with causing or contributing to death. Illicitly manufactured alprazolam, made to look like a popular version known by the trade name Xanax ${ }^{\circledR}$, 
Table 1 Source: "Quantifying the Epidemic of Prescription Opioid Overdose Deaths" P. Seth, PhD, American Journal of Public Health, April 2018; 108(4): 500-502, Table 1 - page 501 (Permission to reproduce chart obtained by John J. Coleman from Cindy Eyler, AJPH, 19 Feb. 2021)

\begin{tabular}{|c|c|c|c|c|c|c|}
\hline \multirow[b]{2}{*}{ Year } & \multicolumn{2}{|c|}{$\begin{array}{l}\text { Conservative Definition for } \\
\text { Prescription Opioids: Natural } \\
\text { and Semisynthetic Opioids } \\
\text { and Methadone }\end{array}$} & \multicolumn{2}{|c|}{$\begin{array}{l}\text { Traditional Definition for } \\
\text { Prescription Opioids: Natural } \\
\text { and Semisynthetic Opioids, } \\
\text { Methadone, and Other } \\
\text { Synthetic Opioids }\end{array}$} & \multicolumn{2}{|c|}{$\begin{array}{l}\text { Synthetic Opioids, Other } \\
\text { Than Methadone' }\end{array}$} \\
\hline & No. & $\begin{array}{l}\text { Overdose Deaths } \\
\text { per } 100000^{6}\end{array}$ & No. & $\begin{array}{l}\text { Overdose Deaths } \\
\text { per } 100000^{6}\end{array}$ & No. & $\begin{array}{c}\text { Overdose Deaths } \\
\text { per } 100000^{\circ}\end{array}$ \\
\hline 1999 & 3442 & 1.2 & 4030 & 1.4 & 330 & 0.3 \\
\hline 2000 & 3785 & 1.3 & 4400 & 1.5 & 782 & 0.3 \\
\hline 2001 & 4770 & 1.7 & 5528 & 1.9 & 957 & 0.3 \\
\hline 2002 & 6483 & 2.3 & 7456 & 2.6 & 1295 & 0.4 \\
\hline 2003 & 7461 & 2.6 & 8517 & 2.9 & 1400 & 0.5 \\
\hline 2004 & 8577 & 2.9 & 9857 & 3.4 & 1664 & 0.6 \\
\hline 2005 & 9612 & 3.2 & 10928 & 3.7 & 1742 & 0.6 \\
\hline 2006 & 11589 & 3.9 & 13723 & 4.6 & 2707 & 0.9 \\
\hline 2007 & 12796 & 4.2 & 14408 & 4.8 & 2213 & 0.7 \\
\hline 2008 & 13149 & 4.3 & 14800 & 4.8 & 2306 & 0.8 \\
\hline 2009 & 13523 & 4.4 & 15597 & 5.0 & 2946 & 1.0 \\
\hline 2010 & 14583 & 4.7 & 16651 & 5.4 & 3007 & 1.0 \\
\hline 2011 & 15140 & 4.9 & 16917 & 5.4 & 2666 & 0.8 \\
\hline 2012 & 14240 & 4.5 & 16007 & 5.1 & 2628 & 0.8 \\
\hline 2013 & 14145 & 4.4 & 16235 & 5.1 & 3105 & 1.0 \\
\hline 2014 & 14838 & 4.6 & 18893 & 5.9 & 5544 & 1.8 \\
\hline 2015 & 15281 & 4.7 & 22598 & 7.0 & 9580 & 3.1 \\
\hline 2016 & 17087 & 5.2 & 32445 & 10.2 & 19413 & 6.2 \\
\hline
\end{tabular}

Note. Deaths are classified according to the International Classification of Diseases, 10th Revision. Drug overdose deaths are identified with underlying cause-of-death codes X40-X44, X60-X64, X85, and Y10-Y14. The following multiple cause-of-death codes were used to identify specific drug types: T40.2 for natural and semisynthetic opioid analgesics, T40.3 for methadone, and T40.4 for synthetic opioid analgesics other than methadone. Approximately one fifth of drug poisoning deaths lack information on the specific drugs involved. Additional information available at: https://www.cdc.gov/drugoverdose/data/analysis.html.

Source. Centers for Disease Control and Prevention. CDC WONDER: Mortality. Atlanta, CA: US Department of Health and Human Services; 2017. Available at: https://wonder.cdc.gov. Accessed December 22, 2017.

'Natural opioids include morphine and codeine, and semisynthetic opioids include drugs such as oxycodone, hydrocodone, hydromorphone, and oxymorphone. Methadone is a synthetic opioid. Synthetic opioids, other than methadone, include drugs such as tramadol and fentanyl.

Deaths may involve one or more drugs.

"Age-adjusted rate, calculated with the direct method and the 2000 standard population. 


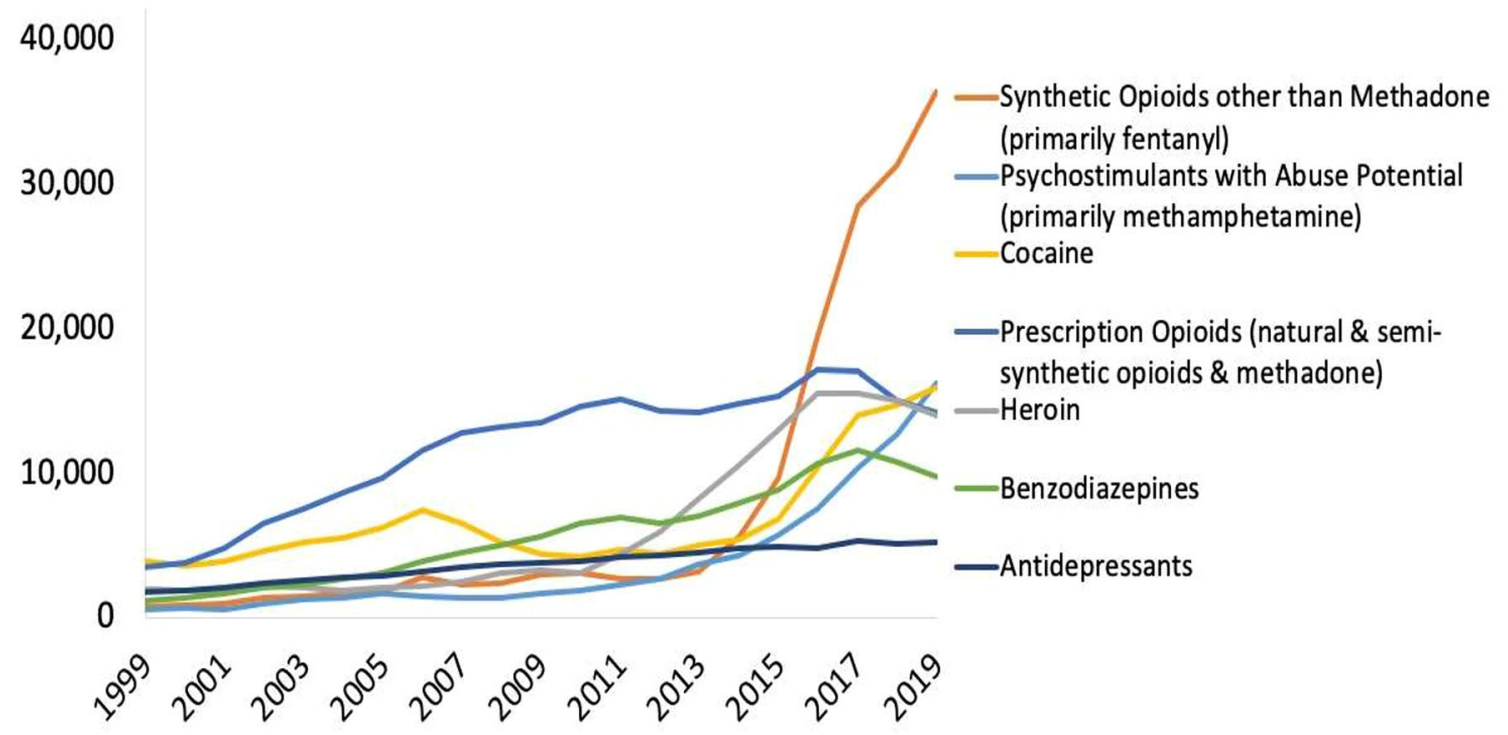

Fig. 3 National drug-involved overdose deaths (including unintentional drug poisoning, suicide drug poisoning, homicide drug poisoning, or drug poisoning of undetermined intent as coded according to the International Classification of Diseases, 10th edition (ICD-10). Data are from Centers for Disease Control and Prevention (CDC, National Center for Health Statistics; Multiple Cause of Death 1999-2019 on CDC WONDER Online Database,

has been reported for sale online or from street drug dealers $[27,28]$. As in the case of IMF, ICD codes do not distinguish between licit and illicit versions of controlled substances containing the same active ingredient.

Similar anomalies in the CDC's use of the ICD for reporting non-opioid drug overdose mortality were identified. For example, cocaine, a controlled substance that is FDA-approved for medical use, is also manufactured illicitly and sold on the street as cocaine or cocaine base (also known as "crack") [29, 30]. Despite important epidemiological differences between the licit and illicit forms of this drug, all references to cocaine in the ICD are categorized under a single T-code (T40.5) [21].

\section{METHADONE: PRESCRIBED FOR PAIN BUT NOT FOR OUD}

A more serious source of potential error involves the CDC's handling of methadone-related released 12/2020; available at: https://wonder.cdc.gov/. (Permission to use graph granted by Josie Anderson, MA, Digital Media Manager, National Institute on Drug Abuse, National Institutes of Health to author John J. Coleman, Ph.D., on 02.25.2021). Original NIDA graphic adapted for use in Fig. 3 is available at: https://www.drugabuse. gov/drug-topics/trends-statistics/overdose-death-rates

overdose deaths. Methadone is a Schedule II opioid agonist with dual indications for the management of severe chronic pain and for treating opioid use disorder (OUD) [31].

When used for pain treatment, methadone is subject to the same regulations as any other Schedule II prescription drug. However, when used for treating OUD, methadone cannot lawfully be prescribed and its use is subject to special state and federal laws [32, 33].

According to federal law, a prescription may not be issued for "detoxification treatment" or "maintenance treatment," unless the prescription is for a Schedule III, IV, or V narcotic drug approved by the Food and Drug Administration (FDA) specifically for use in maintenance or detoxification treatment and the provider has special authorization to prescribe it for these purposes [32, 33]. As a Schedule II controlled substance, methadone cannot lawfully be prescribed for detoxification or maintenance drug treatment. 
Patients admitted for OUD methadone treatment receive the medication under the direct supervision of a practitioner who is authorized to dispense/administer (but not prescribe) the medication in liquid oral form to the patient [31, 34, 35]. Patients must visit the OTP for the first 90 days to be administered daily doses of methadone. After this period, take-home doses of methadone may be approved and dispensed to the patient by the OTP after certain criteria are met $[34,35]$.

Because of the COVID-19 pandemic, the Substance Abuse and Mental Health Services Administration (SAMHSA) has relaxed takehome rules to allow states with declared health emergencies to request exemption for stable methadone patients, regardless of time in the program, to receive as much as 28 days of take-home doses of methadone. While necessary, take-home methadone has been identified with diversion and misuse because of the drug's street value [36]. According to the director of the largest opiate treatment program in Baltimore, a 28-day supply of diverted methadone is worth as much as $\$ 2000$ on the street [37].

According to the CDC, in 2014, methadone accounted for approximately $1 \%$ of all opioids prescribed for pain but was involved in approximately $23 \%$ of all prescription opioid deaths [38]. The CDC did not report how many methadone deaths resulted from the prescribed form (i.e., for pain), and how many methadone deaths resulted from the nonprescribed form (i.e., administered/dispensed for OUD treatment). Citing no evidence other than the total number of deaths from both uses, a CDC report in 2017 claimed that "the preponderance of methadone-associated morbidity and mortality likely arises from its use for pain." [39]

This assumption, however, is not supported by the record. Prescribed methadone dispensed by retail pharmacies in the U.S. decreased $71.2 \%$ between 2010 and 2019 (from 6,068,686.51 g to $1,746,684.03 \mathrm{~g}$ ) [40]. During the same period, the volume of nonprescribed methadone administered/dispensed by opiate treatment programs increased 49.9\% (from 8,746,056.41 g to $13,114,262.44 \mathrm{~g}$ ) [40]. In 2017 , the year that the CDC reported that "the preponderance of methadone-associated morbidity and mortality likely arises from its use for pain," the volume of nonprescribed methadone administered or dispensed by OTPs was more than four-fold the volume of methadone prescribed for pain $(11,686,565 \mathrm{~g}$ administered/dispensed by OTPs vs. $2,740,641 \mathrm{~g}$ prescribed for pain) [40] (see Fig. 4).

The data in Fig. 4 show what appears to be an inverse relationship in the use of methadone between the two populations, i.e., chronic pain patients and opioid use disorder patients. Given what is known about ICD coding and how its use skewed CDC mortality figures for prescribed opioid overdose deaths in 2016, the subject of how the CDC codes methadone-involved deaths demands scrutiny.

On October 5, 2020, in response to a query from the authors of this commentary, Dr. Puja Seth, correspondence author for the 2018 article in question and chief of the CDC's Epidemiology and Surveillance Branch, advised: "As of now, we are unable to tease apart methadone prescribed for pain and methadone administered or dispensed at Narcotic Treatment Facilities "[41]. This brings into play the likelihood that the CDC's annual tally of prescription opioid overdose deaths continues to be skewed by including deaths involving non-prescribed methadone.

\section{THE CDC IGNORED ERROR SIGNALS IN CALCULATING PRESCRIPTION OPIOID OVERDOSE DEATHS}

In their 2018 article, the CDC analysts provided a table showing the calculation of prescription opioid overdose deaths from 1999 to 2016, noting what they termed a "conservative" approach and a "traditional" approach (see Table 1).

By 2013, the number of deaths in the T40.4 category (that includes fentanyl) began to increase sharply after several years of relative stability. By 2016, this category had increased over 525\% (from 3105 deaths in 2013 to 19,413 deaths in 2016). That year, the CDC's data were showing that more than a third $(37.4 \%)$ of all 


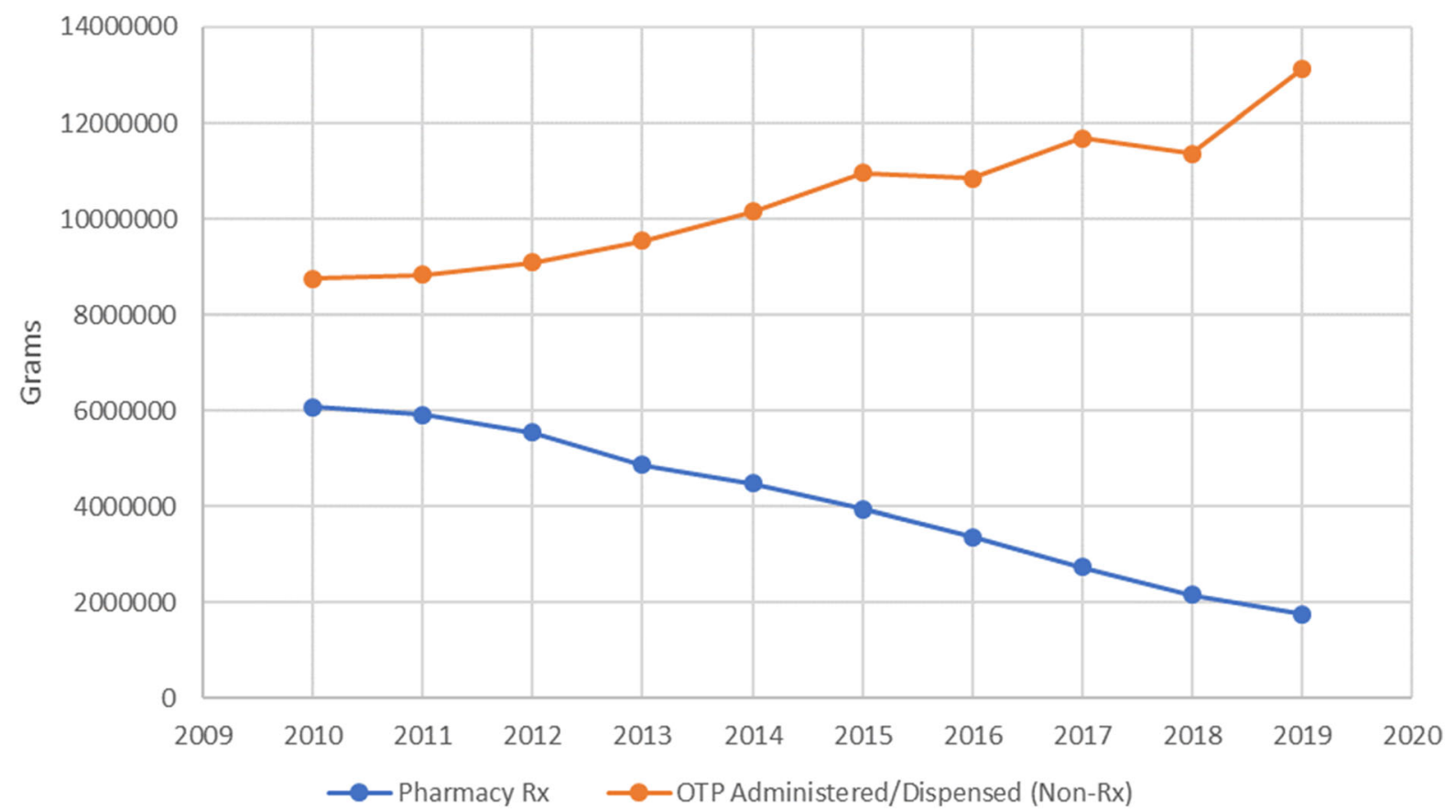

Fig. 4 U.S. methadone distributions to retail pharmacies for filling prescriptions issued for pain management, and U.S. methadone distributions to opioid treatment programs (OTPs) approved and authorized by the Substance Abuse and Mental Health Services Administration to administer or dispense (but not prescribe) to patients being treated for an opioid use disorder (OUD). Data shown in

prescription opioid deaths were caused by "synthetic opioids other than methadone," the T40.4 category that includes fentanyl, pethidine (meperidine), pentazocine, propoxyphene, tapentadol, tramadol, and buprenorphine (see Table 1).

The CDC's data were inconsistent with prescribing data available at the time showing that the volume of fentanyl dispensed by retail pharmacies in the U.S. declined between 2013 and 2016 (see Fig. 5).

Moreover, CDC analysts in the past have asserted a close linear relationship between sales of opioids and opioid overdose deaths, showing that whenever sales increase, they are followed by proportional increases in overdose deaths [42-44]. If the converse of this theory is true, then there should have been a decrease, not an increase, in fentanyl overdose deaths for the period. grams of methadone distributed in calendar years 2010-2019 are from Retail Drug Summary Reports of the Automated Reports and Consolidated Orders System (ARCOS) that is managed by the Drug Enforcement Administration (DEA). These reports are available online at: https://www.deadiversion.usdoj.gov/arcos/retail_drug_ summary/index.html

Instead, according to the CDC's data in Table 1 , three of every five drug overdose deaths $(19,413 / 32,445=59.8 \%)$ in 2016 were coded T40.4 ("Synthetic Opioids, Other Than Methadone"). A rapid increase in overdose deaths caused by T40.4 drugs, a category that includes fentanyl and several other scheduled opioids, did not make sense at a time when the prescribing of these drugs was stable or declining (see Fig. 5).

Buprenorphine, the only T40.4 drug in Fig. 5 showing an increase during this time, like methadone, has a dual indication for treating pain and OUD. Because it is a Schedule III drug, physicians can apply for authorization to prescribe buprenorphine for the treatment of OUD $[45,46]$. DEA distribution records do not differentiate between buprenorphine prescribed for treating pain and buprenorphine prescribed for treating OUD. Given the expansion of out- 


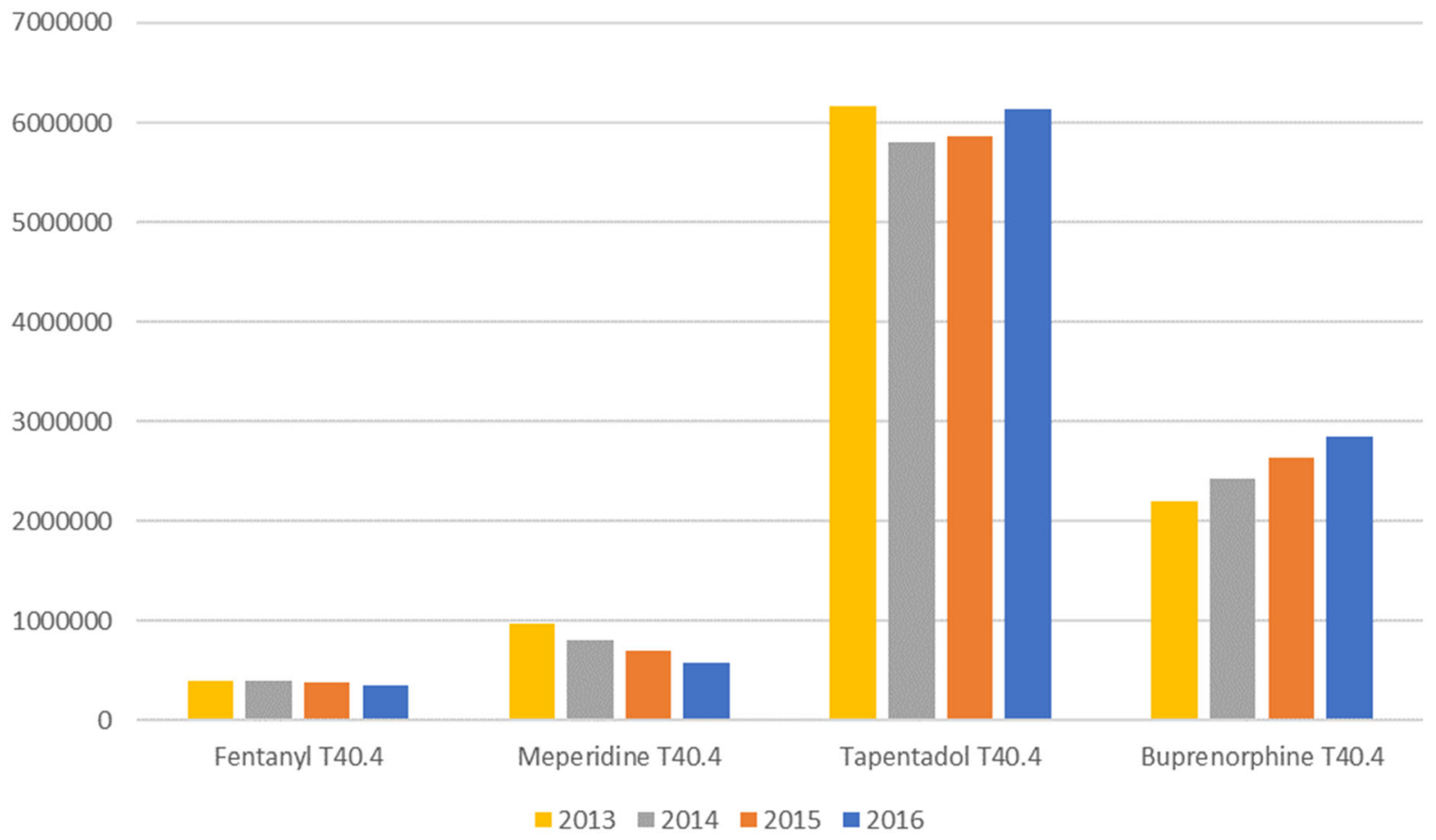

Fig. 5 Prescribing volumes in grams of four popular T-40.4 "synthetic opioids other than methadone" for years 2013, 2014, 2015, and 2016. Data are from Retail Drug Summary Reports of the Automated Reports and Consolidated Orders System (ARCOS) that is managed by the

patient treatment of OUD with buprenorphine in the last decade, it is reasonable to presume the increased volume of prescribed buprenorphine depicted in Fig. 3 reflects the increased prescribing of the drug for OUD treatment [47].

\section{CONCLUSIONS}

Why the CDC ignored signals for years that its methodology for calculating prescription opioid overdose deaths was flawed is unknown. What is clear from the authors' inquiry is that, even today, the CDC has no way of determining the actual number of prescription opioid overdose deaths each year. For more than a decade, the CDC's erroneous reports went unchallenged while being used by Congress and the Executive Branch as the basis for public policy. In just 9 years, from 2012 to 2020 , the federal government expended $\$ 261.3$ billion for drug control
Drug Enforcement Administration (DEA). They reflect distributions to U.S. retail pharmacies for use in filling prescriptions. These reports are available online at: https:// www.deadiversion.usdoj.gov/arcos/retail_drug_summary/ index.html

[48]. It is estimated that the states spent at least as much money, if not more, for the same purpose. The effect of the CDC's reporting failures as discussed herein is unknown. What is known is that the amount of money spent on drug control in the U.S. has continued to increase along with the magnitude of the problem. Perhaps better information would produce better results.

It should be noted that in FY2021 (beginning October 1, 2020), CMS finalized clinical modifications to specifically identify poisonings by fentanyl or fentanyl analogs within the T40.4 coding category [49]. The same treatment was applied to poisonings by tramadol [49]. Unfortunately, these changes did nothing to remedy the IMF problem because they did not offer specific coding definitions for distinguishing illicit from licit fentanyl. As it turns out, the rules for making clinical modifications pose an obstacle to rectifying the core problem of using 
the ICD to compile and report drug-related mortality.

Despite the CDC's difficulty in characterizing prescription opioid overdose deaths, most experts agree that the nation's drug overdose death rate is excessive and continues to trend upward. The CDC reports that over 81,000 drug overdose deaths occurred in the U.S. in the 12 months ending in May 2020 [50]. In a recent report, a chastened CDC offered the following assessment:

"First, approximately $80 \%$ of overdose deaths involved opioids, and three of four opioid overdose deaths involved IMFs. ... Second, IMFs, heroin, cocaine, or methamphetamine (alone or in combination) were involved in nearly $85 \%$ of overdose deaths. Complicating intervention and treatment efforts, one half of these deaths involved two or more of these four drugs "[51] [internal references omitted].

This brief synopsis of the current situation was made by CDC analysts after reviewing detailed mortality reports obtained from 24 CDC-funded state and the District of Columbia officials, the result of a collaborative program [51]. Notably, this assessment is strikingly different in its sensitivity from pre-2018 CDC assessments when IMF was routinely included in the CDC's annual tally of "prescription opioid" overdose deaths.

By providing grants to the states to provide it with information, the $\mathrm{CDC}$ is publishing interim reports like the one cited above that appear to address key policy requirements. Despite this modest improvement, the CDC has not addressed the cause of the error in its mortality reporting in the first place, namely the use of the ICD to code drug overdose deaths in illdefined categories. In addition, the CDC has not yet made public how and if it will respond to the congressional mandate in the 2018 Support for Patients and Communities Act to "modernize" its coding of drug overdose deaths. Less than half the states are currently participating in its enhanced data collection program, leaving the remaining states in the same situation as before.
Why it took more than a decade and a serious opioid abuse crisis, along with a humiliating public acknowledgement in the form of a journal article and a congressional mandate before the CDC addressed some of the deficiencies identified in this commentary remains a perplexing question that should not spare the agency the criticism it deserves. For more than a decade, millions of Americans were misled into believing that-as a White House report once characterized it-"opiate overdoses, once almost always due to heroin use, are now increasingly due to abuse of prescription painkillers" [52]. Little did they know or suspect that the CDC's coding of prescription painkillers included non-prescribed illicitly manufactured fentanyl and fentanyl analogs and non-prescribed methadone administered or dispensed to patients being treated for opioid use disorder.

\section{ACKNOWLEDGEMENTS}

Figures and Tables presented herein are either original to the authors or reproduced with permission from non-copyrighted U.S. Government sources, as cited.

Funding. The authors have received no funding or support for this manuscript from any outside source.

Authorship. Both authors meet the International Committee of Medical Journal Editors (ICMJE) criteria for authorship for this article, take responsibility for the integrity of the work as a whole, and have given their approval for this version to be published.

Disclosures. The authors, John J. Coleman, PhD, and John F. Peppin, D.O., have no personal, financial, commercial, or academic conflicts of interest. At the time of study, John J. Coleman was a retired Assistant Administrator for Operations at the U.S. Drug Enforcement Administration and the current President of the Board of Directors at Drug Watch International Inc. John F. Peppin is currently a consultant and medical monitor at Relmada Therapeutics. 
Within the last 12 months, John. F Peppin was a consultant and medical monitor at US WorldMeds (last contact April 2020) and a consultant at West Therapeutics (last contact April 2020). John F. Peppin is also a member of the journal's Editorial Board.

Compliance with Ethics Guidelines. This article is based on previously conducted and published studies and does not contain any new studies with human participants or animals performed by any of the authors.

Data Availability. The datasets generated during and/or analyzed during the current study are available from the corresponding author upon reasonable request.

Open Access. This article is licensed under a Creative Commons Attribution-NonCommercial 4.0 International License, which permits any non-commercial use, sharing, adaptation, distribution and reproduction in any medium or format, as long as you give appropriate credit to the original author(s) and the source, provide a link to the Creative Commons licence, and indicate if changes were made. The images or other third party material in this article are included in the article's Creative Commons licence, unless indicated otherwise in a credit line to the material. If material is not included in the article's Creative Commons licence and your intended use is not permitted by statutory regulation or exceeds the permitted use, you will need to obtain permission directly from the copyright holder. To view a copy of this licence, visit http://creativecommons.org/licenses/by$\mathrm{nc} / 4.0 /$.

\section{REFERENCES}

1. Department of Health and Human Services. National Center for Health Statistics, DHHS, CDC: Celebrating 50 years. 2010 [April 22, 2020]; Available from: https://www.cdc.gov/nchs/data/about/nchs_ 50th_brochure.pdf.

2. National Vital Statistics System (CDC). A Reference Guide for Completing the Death Certificate for Drug Toxicity Deaths. 2019 [October 17, 2020];
Available from: https://www.cdc.gov/nchs/data/ nvss/vsrg/vsrg02-508.pdf.

3. Centers for Disease Control and Prevention. Coroner/Medical Examiner Laws, by State. 2016 [October 17, 2020]; Available from: https://www.cdc. gov/phlp/publications/topic/coroner.html.

4. Robert Anderson. Chief, Mortality Statistics Branch, CDC; Maternal deaths in the National Vital Statistics System (PPT presentation to the NCHS Board of Scientific Counselors, Hyattsville, MD, May 9-10, 2019). 2019 [January 12, 2021]; Available from: https://view.officeapps.live.com/op/view.aspx?src= https $\% 3 \mathrm{~A} \% 2 \mathrm{~F} \% 2 \mathrm{Fwww} . \mathrm{cdc}$.gov $\% 2 \mathrm{Fnch} \% 2 \mathrm{Fdata} \%$ 2Fbsc\%2Fbsc_pres_anderson_maternal_may_2019. pptx.

5. Krywanczyk A, et al. Autopsy service death certificate review. Arch Pathol Lab Med. 2020;144(9): 1092-6.

6. Jessica Priest, One in 3 death certificates were wrong before coronavirus. It's about to get even worse, in USA Today (April 25 ed.). 2020.

7. Horon IL, et al. Standard death certificates versus enhanced surveillance to identify heroin overdoserelated deaths. Am J Public Health. 2018;108(6): 777-81.

8. Buchanich JM, et al. The effect of incomplete death certificates on estimates of unintentional opioidrelated overdose deaths in the united states, 1999-2015. Public Health Rep. 2018;133(4):423-31.

9. Fugelstad A, et al. Drug-related deaths: statistics based on death certificates miss one-third of cases. Scand J Public Health. 2017;0(0): 1403494817745187.

10. Fischtein D, Cina SJ. Errors on death certificates requiring amendments: the Broward County experience. Am J Forensic Med Pathol. 2011;32(2): $146-8$.

11. Jessica Priest, One in 3 death certificates were wrong before coronavirus. It's about to get even worse (Corrected Copy by USA Today), in USA Today (April 25 ed.). 2020.

12. Centers for Disease Control and Prevention. National Vital Statistics System: Mortality Statistics. 2021 [January 17, 2021]; Available from: https:// www.cdc.gov/nchs/nvss/deaths.htm.

13. Centers for Disease Control and Prevention. Instruction Manual, Part 11, Computer Edits for Mortality Data, Including Separate Section for Fetal Deaths Effective 20102009 [January 17, 2021]. 
14. Centers for Disease Control and Prevention. National Center for Health Statistics: Accidents or Unintentional Injuries. 2020 [August 16, 2020]; Available from: https://www.cdc.gov/nchs/fastats/ accidental-injury.htm.

15. Weathermon R, Crabb DW. Alcohol and medication interactions. Alcohol Res Health. 1999;23(1): 40-54.

16. Ogbu UC, Lotfipour S, Chakravarthy B. Polysubstance abuse: alcohol, opioids and benzodiazepines require coordinated engagement by society, patients, and physicians. West J Emerg Med. 2015;16(1):76-9.

17. Centers for Disease Control and Prevention. Instructions for Completing the Cause-of-Death Section of the Death Certificate. 2004 [September 22, 2020]; Available from: https://www.cdc.gov/ nchs/data/dvs/blue_form.pdf.

18. Taylor A, Frischer M, Goldberg D. Non-fatal overdosing is related to polydrug use in Glasgow. BMJ. 1996;313(7069):1400-1.

19. Grider DJ. Preparing For ICD-10-CM: make the transition manageable. Chicago: American Medical Association; 2010.

20. World Health Organization, International Classification of Diseases. ICD-10 Version: 2016: Chapter XIX, T40 Poisoning by narcotics and psychodysleptics [hallucinogens]. 2016 [November 11, 2018]; Available from: http://apps.who.int/ classifications/icd10/browse/2016/en\#T40.5.

21. Centers for Disease Control and Prevention. ICD10-CM Table of Drugs and Chemicals. 2019 [January 30, 2019]; Available from: ftp:/ftp.cdc.gov/ pub/Health_Statistics/NCHS/Publications/ ICD10CM/2019/icd10cm_drug_2019.pdf.

22. Seth P, et al. Quantifying the epidemic of prescription opioid overdose deaths. Am J Public Health. 2018;108(4):500-2.

23. Centers for Disease Control and Prevention. Morbidity and Mortality Weekly Report (June 20, 2014/ 63(24);531): Notes from the Field: Increase in Fentanyl-Related Overdose Deaths - Rhode Island, November 2013-March 2014. 2014 [November 21, 2018]; Available from: https://www.cdc.gov/ mmwr/pdf/wk/mm6324.pdf.

24. Centers for Disease Control and Prevention. Notes from the field: acetyl fentanyl overdose fatalities: Rhode Island, March-May 2013. Morb Mortal Wkly Rep. 2013;62(34):703-4.

25. U.S. Congress. Support for Patients and Communities Act, H.R. 6, 115th Congress, Public Law No.
115-271 (Oct. 24, 2018). 2018 [December 24, 2018]; Available from: https://www.congress.gov/bill/ 115th-congress/house-bill/6/actions?q=\%7B\% 22 search $\% 22 \% 3 \mathrm{~A} \% 5 \mathrm{~B} \% 22 \mathrm{HR}+6 \% 22 \% 5 \mathrm{D} \% 7 \mathrm{D} \& \mathrm{r}=$ $1 \& s=1$.

26. National Institute On Drug Abuse. Overdose Death Rates. 2020 [November 21, 2020]; Available from: https://www.drugabuse.gov/drug-topics/trendsstatistics/overdose-death-rates.

27. U.S. District Court, District of Utah. USA v. Arron Michael Shamo, et al.; Case 2:16-cr-00631-PMW, Doc. \#32 (Superseding Indictment). Filed 05/31/ 2017. 2017; Available from: https://ecf.utd. uscourts.gov/doc1/18313985299.

28. Drug Enforcement Administration. Champaign man sentenced to 13 years in prison for trafficking. 2020 [January 16, 2021]; Available from: https:// www.dea.gov/press-releases/2020/01/06/ champaign-man-sentenced-13-years-prisontrafficking.

29. Controlled Substances Act. Title 21, United States Code, Sect. 812; Schedules of controlled substances. 1970 [May 8, 2017]; Available from: http://uscode. house.gov/search/criteria.shtml.

30. Drug Enforcement Administration. Drug Fact Sheet: Cocaine. 2020 [October 22, 2020]; Available from: https://www.dea.gov/factsheets/cocaine.

31. Substance Abuse and Mental Health Services Administration. Methadone. 2020 [October 10, 2020]; Available from: https://www.samhsa.gov/ medication-assisted-treatment/medicationscounseling-related-conditions/methadone.

32. Code of Federal Regulations. 21 CFR 1306.o4 Purpose of Issue of Prescription. 2020 [October 13, 2020]; Available from: https://www.ecfr.gov/cgibin/text-idx?SID= 6ca40ca4231f0186f9b323f4e1f23206\&mc= true\&node=pt21.9.1306\&rgn=div5\#se21.9.1306_ 104.

33. U.S. Code. Title 21, Section 823(g) Practitioners dispensing narcotic drugs for narcotic treatment; annual registration; separate registration; qualifications; waiver. 2020 [October 13, 2020]; Available from: https://www.govinfo.gov/content/pkg/ USCODE-2018-title21/pdf/USCODE-2018-title21chap13-subchapI-partC-sec823.pdf.

34. Code of Federal Regulations. Title 42, CFR Sect. 8.12 Federal opioid treatment standards. 2019 [September 29, 2020]; Available from: https://www.govinfo. gov/content/pkg/CFR-2019-title42-vol1/pdf/CFR2019-title42-vol1.pdf. 
35. Department of Health and Human Health Services. Resources for Opioid Treatment Providers. 2020 [September 29, 2020]; Available from: https://www. hhs.gov/opioids/treatment/resources-opioidtreatment-providers/index.html.

36. Varenbut $M$, et al. Tampering by office-based methadone maintenance patients with methadone take home privileges: a pilot study. Harm Reduct J. 2007;4:15.

37. Prudente, T., Those addicted to drugs are being sent home with more methadone than ever, in The Washington Post. 2020.

38. Centers for Disease Control and Prevention. Methadone prescribing and overdose and the association with Medicaid preferred drug list policiesUnited States, 2007-2014. Morb Mortal Wkly Rep (MMWR). 2017;66(12):320-3.

39. Faul M, Bohm M, Alexander C. Methadone prescribing and overdose and the association with Medicaid preferred drug list policies-United States, 2007-2014. Morb Mortal Wkly Rep (MMWR). 2017;66:12.

40. Drug Enforcement Administration. Office of Diversion Control: ARCOS Retail Drug Summary Reports. 2020 [November 25, 2020]; Available from: https:// www.deadiversion.usdoj.gov/arcos/retail_drug summary/index.html.

41. Seth, P., RE: Inquiry re: CDC reporting of prescription opioid overdose deaths (email dated Oct. 6, 2020), J.J. Coleman, Editor. 2020: Unpub.

42. Paulozzi LJ, Weisler RH, Patkar AA. A national epidemic of unintentional prescription opioid overdose deaths: how physicians can help control it. J Clin Psychiatry. 2011;72(5):589-92.

43. Paulozzi LJ, Budnitz DS, Xi Y. Increasing deaths from opioid analgesics in the United States. Pharmacoepidemiol Drug Saf. 2006;15(9):618-27.

44. Johnson $\mathrm{H}$, et al. Decline in drug overdose deaths after state policy changes-Florida, 2010-2012. MMWR Morb Mortal Wkly Rep. 2014;63(26): 569-74.

45. Substance Abuse and Mental Health Services Administration. Buprenorphine. 2020; Available from: https://www.samhsa.gov/medication- assisted-treatment/medications-counseling-relatedconditions/buprenorphine.

46. Federal Register. Final Rule - Drug Enforcement Administration: Schedules of Controlled Substances: Rescheduling of Buprenorphine From Schedule V to Schedule III [67FR62354]. 2002 [October 15, 2020]; Available from: https://www. govinfo.gov/content/pkg/FR-2002-10-07/pdf/0225293.pdf.

47. Roehler DR, Guy GP Jr, Jones CM. Buprenorphine prescription dispensing rates and characteristics following federal changes in prescribing policy, 2017-2018: a cross-sectional study. Drug Alcohol Depend. 2020;213:108083.

48. Office of National Drug Control Policy. National Drug Control Strategy: FY 2020 Budget Summary. 2020 [September 25, 2020]; Available from: https:// www.whitehouse.gov/wp-content/uploads/2020/ 02/FY-2021-National-Drug-Control-BudgetHighlights.pdf.

49. Centers for Medicare and Medicaid Services. Final FY2021 ICD-10 Code Updates - Summary of Changes - IPF-PPS. 2020 [November 30, 2020]; Available from: https://www.cms.gov/files/document/fy2021-addendum-b-ipf-pps-final-rule-icd-10-codefirst-update.pdf.

50. Centers for Disease Control and Prevention. Overdose Deaths Accelerating During COVID-19. 2021 [January 17, 2021]; Available from: https://www. cdc.gov/media/releases/2020/p1218-overdosedeaths-covid-19.html.

51. Julie O'Donnell CDC. Vital signs: characteristics of drug overdose deaths involving opioids and stimulants-24 states and the district of Columbia, January-June 2019. Morb Mortal Wkly Rep. 2020;69(35):1189-97.

52. The White House. Epidemic: Responding to America's Prescription Drug Abuse Crisis. 2011 [April 28, 2020]; Available from: https://www.hsdl.org/ ?view\&did=4609.

53. Coleman, J.J. (2019) Why Death Certificates are Unreliable Source Data for Compiling and Reporting Drug-Related Mortality (PPT presentation given June 9, 2019, at the International Conference on Opioids, Joseph B. Martin Conference Center at Harvard Medical School, Boston, MA) [September 24, 2020]. 